\title{
Erratum to: A model-dependent approach to the non-relativistic Lamb shift
}

J.F. Diaz-Valdes ${ }^{1, a}$ and S.A. Bruce ${ }^{2, b}$

1 Universidad de Concepcion, Departamento de Fisica, Concepcion, Chile

${ }^{2}$ Universidad de Los Andes, Facultad de Ingeniería y Ciencias Aplicadas, Complex Systems Group, Santiago, Chile

Original article: Eur. Phys. J. Plus (2018) 133: 76, https://doi.org/10.1140/epjp/i2018-11906-3

Received: 12 September 2018

Published online: 21 December 2018

(C) Società Italiana di Fisica / Springer-Verlag GmbH Germany, part of Springer Nature, 2018

After publication of the paper, the authors realized that fig. 1 and its caption were incorrect. Here is their corrected versions.

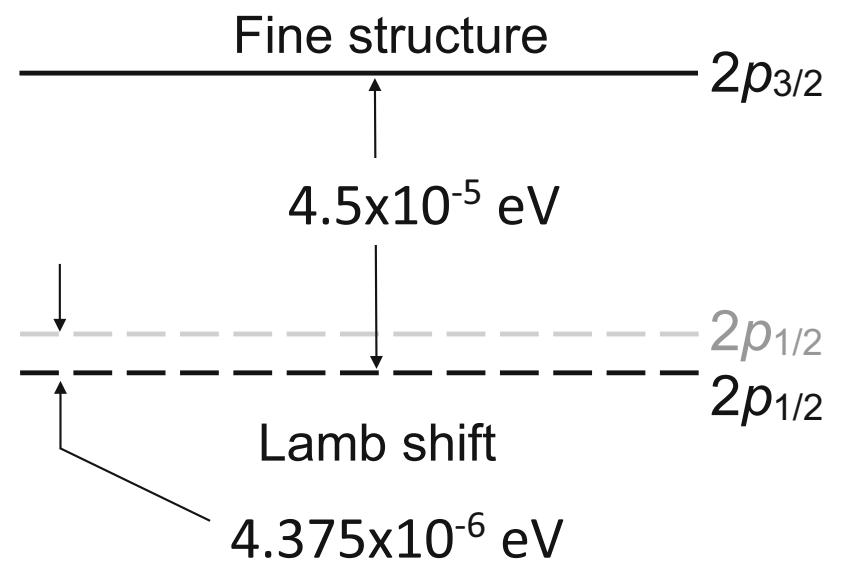

Fig. 1. Energy level diagram for the $n=2$ state of the hydrogen atom with the corresponding Lamb shift and fine structure.

a e-mail: jdiaz@udec.cl (corresponding author)

b e-mail: sbruce@miuandes.cl 